\title{
How Genealogies Can Affect the Space of Reasons
}

\author{
MATTHIEU QUELOZ \\ Philosophy, University of Basel
}

\begin{abstract}
Can genealogical explanations affect the space of reasons? Those who think so commonly face two objections. The first objection maintains that attempts to derive reasons from claims about the genesis of something commit the genetic fallacy-they conflate genesis and justification. One way for genealogies to sidestep this objection is to focus on the functional origins of practices- to show that, given certain facts about us and our environment, certain conceptual practices are rational because apt responses. But this invites a second objection, which maintains that attempts to derive current from original function suffer from continuity failure - the conditions in response to which something originated no longer obtain. This paper shows how normatively ambitious genealogies can steer clear of both problems. It first maps out various ways in which genealogies can involve non-fallacious genetic arguments before arguing that some genealogies do not invite the charge of the genetic fallacy if they are interpreted as revealing the original functions of conceptual practices. However, they then incur the burden of showing that the conditions relative to which practices function continuously obtain. Taking its cue from the genealogies of E. J. Craig, Bernard Williams, and Miranda Fricker, the paper shows how model-based genealogies can avoid continuity failures by identifying bases of continuity in the demands we face.
\end{abstract}

$A$ GAINST the widespread view that explanations of how something argue in this paper that genealogical explanations can be used to affect the space of reasons. I do this by showing how genealogies can overcome two objections thought to form stumbling-blocks for normatively ambitious genealogies purporting to subvert or vindicate their object. The first objection maintains that attempts to derive reasons from claims about the genesis of something commit the genetic fallacy - they conflate genesis and justification. ${ }^{2}$ There are basically two ways of side-stepping this objection.

1 See, inter alia, Dutilh Novaes (2015); Finken (2012); Fraser (1981); Glock (2008a; 2008b, p. 101); Goudge (1961); Hamblin (2004, p. 45); Hanson (1967); Hoy (1994); Kaplan (2002, p. 13); Kim (1990); Koopman (2013, p. 20); Rosenbaum (2002); Wiener (1946). The widespread view is that genealogies can advance our understanding of philosophically puzzling concepts, but that they do not directly justify or debunk them (Dutilh Novaes 2015, pp. 100-101).

2 This objection was raised against Bernard Williams's genealogy by Colin Koopman (2013, p. 20). For further discussions which see the genetic fallacy as clouding the prospects of normatively ambitious genealogical explanations, see Finken (2012); Fraser (1981); Glock (2008a; 2008b, p. 101); Goudge (1961); Hamblin (2004, p. 45); Hanson (1967); (Hoy 1994); Kaplan (2002, p. 13); Kim (1990); Koopman (2013, p. 20); Rosenbaum 
One is to show that the genealogies in question involve non-fallacious genetic arguments; the other is to show that correctly understood, these genealogies do not invite the charge of the genetic fallacy, because they do not really involve genetic arguments at all. In the interest of thoroughness, I will indicate viable versions of both strategies, ${ }^{3}$ and also defend genealogies with normative import against the main charge they run into when they are not interpreted as involving genetic arguments. I will first map out various ways in which genealogies can involve non-fallacious genetic arguments. I will then show that some genealogies do not invite the charge of the genetic fallacy if they are interpreted as genealogical inquiries into the functional origins of our conceptual practices (a catch-all term meant to cover concepts, values, virtues, and other practices of epistemic and normative assessment). On the reading I shall offer, these genealogies can yield pragmatic vindications of these conceptual practices by showing how, given particular facts about the needs of concept-users in particular circumstances, certain conceptual practices are rational because apt responses.

As a result of this functionalist interpretation, however, these genealogies invite a second objection akin to the charge of the genetic fallacy. The objection is that genealogies which try to derive current from original function suffer from continuity failure - they founder on the fact that the conditions in response to which something originated no longer obtain. ${ }^{4}$ As Nicholas Smyth (2017) has recently argued in response to the genealogies of Richard Joyce (2006), Jesse Prinz (2007), and Philip Kitcher (2011), ${ }^{5}$ ascriptions of current functionality on the basis of genealogy are warranted only if the conditions relative to which something was originally functional still

(2002); Wiener (1946). For more optimistic assessments, see Crouch (1991, 1993); Dutilh Novaes (2015); Klement (2002); Lavine (1962); Sober (1994); Ward (2010).

3 This two-pronged approach takes care of the lack of consensus over what counts as a genetic argument and what counts as a genetic fallacy: any given normatively ambitious genealogy either involves a genetic argument or it does not; if it does, section 1 lays out how this argument can avoid the genetic fallacy; if it does not, the genealogy is not at risk of committing the genetic fallacy in the first place; but then-so I argue-it is likely to be at risk of foundering on continuity failure (which on some understandings would also count as a form of the genetic fallacy); if it is, section 3 lays out how such a genealogy can avoid continuity failure; either way, it emerges that neither the genetic fallacy nor continuity failure are insuperable stumbling-blocks for normatively ambitious genealogies.

4 Smyth (2017). I discuss Smyth's objection in detail in $\S 2$.

5 Looking beyond disciplinary boundaries, one might also include Jonathan Haidt (2012), Joshua Greene (2013), and Michael Tomasello (2016). 
obtain, and Smyth suggests that these genealogies founder on continuity failure.

A successful genealogy with normative import must therefore steer clear of the genetic fallacy without foundering on continuity failure. A model for how to do this, I argue, is provided by the state-of-nature-based genealogical inquiries into the point of individual concepts and virtues offered by E.J. Craig (1990), Bernard Williams (2002), and Miranda Fricker (2007). I suggest that these genealogies are best read as making ascriptions of current functionality based on genealogical inquiries into structural origins, i.e. into facts about us and our environments that our practices are rooted in and arise in answer to. ${ }^{6}$ Although these genealogies can draw on historical information, they are closer to dynamic model-building than to standard historiography. ${ }^{7}$ Yet they are still properly called genealogical. This comes out if we contrast them with their explicitly non-genealogical sibling that Fricker went on to develop: these so-called paradigm-based explanations take an actual paradigm case of a given practice, hypothesise its point given the needs of actual parties to the practice, and explain further cases of the practice as elaborations of the paradigm case serving the same point in different ways. ${ }^{8}$ The genealogies of Craig, Williams, and Fricker differ from paradigm-based explanations in two respects: first, they set out from constructed models or idealised prototypes of our practices rather than from the actual practices themselves; and second, they introduce a developmental axis to understand how and why we might have gotten from these prototypes to the practices we in fact have. In contrast to paradigm-based explanations, these genealogies start out from a primitive form of a solution

6 Yet they are not inquiries into transcendent and "immobile forms" preceding the flux of history of the kind that Foucault (1971) rejected in favour of inquiries into the multiple causes of the emergence of things. For more on Foucault's notion of emergence, see Koopman (2013, pp. 39-44). For a conciliatory discussion of Foucault's critique of the search for "origins" in relation to the genealogies of Craig and Williams, see Fricker (Forthcoming). As Fricker also notes, the key point is that their genealogies are concerned with practical necessity rather than metaphysical necessity.

7 This focus on genealogies that are interpretable as primarily constituting a form of model-building rather than a form of documentary historiography is the reason why I do not explicitly discuss the better-known genealogies of Nietzsche and Foucault (although the broader discussion of the genetic fallacy in section 1 implicitly encompasses them as well). This is not to deny that at least where Nietzsche is concerned, some genealogical passages may be amenable to such an interpretation. But arguing the point here would take us too far afield. For readings of some of Nietzsche's early genealogies in this direction, see Queloz (2017b, Forthcoming-a, Manuscript).

8 See Fricker (2016, Forthcoming). 
to a basic problem that is not and indeed could not be actual in a stable way (which is why a fictional construct is called for). For example, Williams begins his genealogy with prototypical forms of truthfulness- "Accuracy" and "Sincerity" — which, at the beginning of his genealogy, are understood in purely instrumental terms as means to foster the flow of information, but prove unstable as long as they are sustained only by instrumental concerns. The value of starting from such an idealization lies in the stark simplicity with which it brings out the functional pressures that both require a solution along these lines and require it to develop beyond that primitive form. ${ }^{9}$ But this approach is genealogical not only in considering these functional origins. It is also genealogical in two further respects: first, in considering the primitive form's elaboration in response to further generic needs anticipatable from within the model (in Craig's genealogy, this is exemplified by the gradual "objectivisation" of the concept of knowledge, i.e. its development into a concept that is less directly tied to subjective needs) ${ }^{10}$ and second, in considering the primitive form's elaboration in response to increasingly socio-historically local needs. Based on historical information, the genealogical explanation is progressively tailored to the practices that we have, now and around here (in Williams's genealogy, this is exemplified by the elaboration of Accuracy to encompass statements about the distant past in response to developments in Ancient Greece, or by that of Sincerity to encompass the demand for authenticity in response to developments in the Romantic period). ${ }^{11}$ If the genealogist ends up with something sufficiently like our local form of the practice in question, he or she will have a reasonable claim to having explained why we might have come by the practice in terms of its original point and subsequent elaboration in response to historically situated needs.

Such a reading of the genealogies of Craig, Williams, and Fricker raises many questions worth pursuing, but in this paper, I shall restrict myself to just one aspect: how these genealogies suggest a way of tackling the

9 Contra McGinn (2003), the genealogical dimension is thus more than a colourful but ultimately superfluous illustration. I offer a fuller defence of Williams's genealogy against this objection in Queloz (Forthcoming-b).

${ }^{10}$ Craig (1990, chs. 10-12; 1993, ch. 3).

${ }^{11}$ Williams (2002, chs. 7-8). Here, as he puts it, philosophy must involve itself in history in order to achieve what it sets out to achieve $(2002,93)$. Another example of a functional genealogy that is progressively tailored to a particular socio-historical situation is Williams's derivation of the modern liberal idea of liberty from a generic and primitive idea of freedom (Williams 2005b). 
problem of continuity failure. My contention will be that they put us in a position to reveal a practice's functionality for us while deriving the need for the continual discharge of that function from persistent facts about the kinds of creatures we are. Such genealogies thereby avoid assuming continuity in the practical demands we face, because precisely what they are is attempts to identify bases of continuity in those demands. They are not arguments depending on continuity, but arguments for it.

\section{Two Ways of Connecting Origin and Justification}

For our purposes, the genetic fallacy can be understood as the error of treating items in the context of formation of conceptual practices as if they belonged to the context of justification when in fact they do not. ${ }^{12}$ We can acknowledge that there is such an error without committing ourselves to the much stronger claim that nothing can be inferred about the justification of something solely from facts about its origins. ${ }^{13}$ Items in the context of formation can form part of the context of justification, but they

\footnotetext{
12 This understanding is adapted from Salmon (1973, p. 11). Alternative characterisations of the genetic fallacy maintain that it consists in judging the truth of an assertion on the basis of its source rather than by the evidence or argument available for it (Kaplan 2002 , p. 13), or conflating temporal or historical origin with logical nature (Hamblin 2004, p. 45; Koopman 2013, p. 20; Rosenbaum 2002; Wiener 1946). Glock defines it as "the mistake of deducing claims about the validity of a theory or the content of a concept from information about its historical origins, including information about the causes of its emergence" (2008b, p. 101). The Oxford Dictionary of Philosophy defines it as "any mistake of inferring something about the nature of some topic from a proposition about its origins" (Blackburn 2016, p. "genetic fallacy"). Inferring current from ancestral function is also sometimes described as a genetic fallacy (Dennett 1995, 465). Finken (2012) even brings the acceptance of a belief for pragmatic reasons under that heading. Hanson (1967) argues that these various uses share nothing but their name and the fact that they involve some kind of inference from historical statements to statements which are not merely historical. Similarly, Goudge (1961) claims that there is no single mistake in reasoning which goes by the name of "genetic fallacy"; rather, the name designates a cluster of mistakes associated with the giving of genetic explanations.

13 This is argued at length by Sober (1994). Other defences of genetic reasoning include Klement's (2002) vindication of a certain form of self-referential abductive reasoning. Ward (2010) sees a role for modest, inductive genetic reasoning: it acts as a corrective against prejudice by calling into question (without conclusively undermining) justifications coming from particular sources. Lavine (1962) offers a defence of a functionalist version of genetic reasoning: to understand the function of something requires understanding what it is functional for, and this in turn requires relating it to the situation to which it answers. For a qualified defence of genetic reasoning relating the history to the philosophy of science, see Hanson (1967). For a similarly qualified defence of genetic reasoning in the context of feminist philosophy, see Crouch (1991). Crouch (1993) also offers a more general defence by problematising the distinction between the contexts of discovery and justification.
} 
can properly do so only if there is a connection between an aspect of the context of formation and the justification of the item in question. What is fallacious is not the inference from origins to justification per se, but the inference from irrelevant information about origins to justification. And of course, whether some piece of information is relevant to the justification of a given conclusion is often precisely what is at issue. What normatively ambitious genealogical explanations depend on, then, is that there be such a connection rendering some aspect of the context of formation relevant to the context of justification. ${ }^{14}$ The charge of the genetic fallacy thus serves as a reminder that contexts of formation and contexts of justification are distinct spheres. Yet there may be overlaps-peculiarities of one sphere which lead it to extend into the other. As this image already indicates, this can happen in one of two ways. Either the space of reasons is itself such that it locally encompasses certain formation processes; or these formation processes are such that knowledge of them can contribute to the vindication or subversion of their objects. Either we have genetically justified practices, or we have genealogies yielding justifications.

Take genetically justified practices first. Claims about the formation processes of conceptual and evaluative practices may affect the space of reasons because these claims concern practices whose authority is itself a function of their formation. ${ }^{15}$ That is to say, formation processes are part of the truth conditions of the propositions from which the practice derives its authority. We may call practices which understand themselves or claim authority for themselves in terms which knowledge of their formation can undermine genetically justified practices. Examples of such genetically justified practices abound in politics and law, where it is common for practices to derive their authority from the procedure by which they were formed. In a democracy, for instance, a decision might be legitimated by the fact that it is the product of a democratic procedure. Similarly, many rituals and traditions justify

14 Pashman (1970) argues that relevance depends on there being a causal link between the context of formation and the context of justification. But in many cases, no such philosophically neutral ways of determining relevance will be available: the Archimedean standpoint is lacking (Crouch 1993; Srinivasan 2015). Crouch argues that it should not be surprising that philosophies that draw on Marxist or Freudian explanations seem to commit the genetic fallacy. The genetic fallacy was formulated largely in opposition to just the kinds of assumptions on which these theories depend. Feminist theories, insofar as they accept these assumptions, will also appear to commit the genetic fallacy. Crouch (1991) offers a nuanced evaluation.

${ }^{15}$ See Williams (2014b, p. 410) and Gutting (2005, p. 50). 
their continuation by reference to their authoritative origins-things are done a certain way because some respected originator of the ritual or tradition did them that way. A particularly striking example is the Catholic notion of apostolic succession, according to which the spiritual authority of present-day clerics derives from the uninterrupted transmission (through successive popes and bishops) of the original authority of the Apostles. Indeed, it is characteristic of religious practices that they revolve around wide-screen representations of their own origins from which they derive their self-understanding and authority.

In all these cases, genealogical explanations can impinge on the space of reasons because the rational articulation of the conceptual and evaluative practices in question itself refers to their formation. Whether a practice is genetically justified or not is something to be determined by looking at how it presently functions. When practices are genetically justified, however, this justificatory connection to their own formation renders them susceptible to vindication and subversion by genealogical explanations. The structure of such vindications and subversions will then be as follows:

Vindicatory Genealogy of a Genetically Justified Practice:

conceptual practice $P$ understands itself or claims authority for itself in terms of a representation $R_{F P}$ of its own formation process $F P$.

Inquiry into how FP might have given rise to $P$ suggests that $R_{F P}$ is true. Therefore, the authority of $P$ is to that extent vindicated.

Subversive Genealogy of a Genetically Justified Practice:

conceptual practice $P$ understands itself and claims authority for itself in terms of a representation $R_{F P}$ of its own formation process $F P$.

Inquiry into how FP might have given rise to $P$ suggests that $R_{F P}$ is false. Therefore, the authority of $P$ is to that extent subverted.

I take it that this is the standard way in which genealogy has been thought to overcome the genetic fallacy: by exploiting the fact that the target phenomenon understands itself and claims authority for itself in terms which a genealogy can undermine. For example, liberalism has been claimed to be the product of reason's march through history - the rationally inevitable endpoint of a historical process of becoming alive to universal reasons. ${ }^{16} \mathrm{~A}$

\footnotetext{
16 This is a point of contention between Thomas Nagel $(1997,2009)$ and Bernard Williams (2014a), for example. Williams writes: "[W]hen it is argued that the values of contemporary liberalism cannot possibly be criticised in terms of their history, this will be so only to the extent that those values can be separated from the claim-one which is often made for them - that they have emerged from the spread of reason and represent a cognitive achievement" (2014b, p. 410). See Queloz (2017a) for further discussion.
} 
genealogical inquiry into the actual formation process of liberalism might throw doubt on this representation, and thereby subvert the authority liberalism claims for itself in terms of the march of reason. More generally, a genealogy can sap the authority of beliefs or ideas by revealing their contingency insofar as these demand authority for themselves in terms that are incompatible with that contingency.

This is not to deny that genealogy can also have more indirect effects on authority. ${ }^{17}$ Even when a practice appears normal, natural, or necessary without its authority depending on its being taken to be so, genealogical inquiry can enable a critical reevaluation of authority. It primarily does this by showing that people can live differently, because they have lived differently. Generating this sense of alternatives pulls aside the veneer of inevitability. This is not itself a subversion of authority. But, as Elisabeth Anderson has put it, it converts dogmas into tools that we can choose to use or not (2001, p. 22). It turns dogmatic acceptance into critical assessment.

However, there are other ways in which genealogy can impinge on the space of reasons which we miss if we focus only on contingency. These other ways are not a matter of how practices claim authority for themselves, but of how and why they originated. This is where we turn from genetically justified practices to genealogies yielding justifications.

In this second way of connecting origin and justification, it is not the justificatory structures, but the formation processes themselves which are such that knowledge of them can contribute to a vindication or subversion of practices, or simply exhibit them as rationally contingent. Let us say that a practice $P$ is rationally contingent to the extent that the considerations contributing to the best explanation of why a group $G$ engages in $P$ fail to provide reasons to prefer $P$ over possible rivals to $P$, where possible rivals to $P$ are unrealised alternatives to $P$ competing for the place in our lives occupied by $P$, and notably include the abandonment of $P$. We can then distinguish three ways in which insights into the formation process of a practice can bear on our understanding of it:

Vindicatory Genealogy:

Group $G$ engages in conceptual practice $P$.

${ }_{17}$ Koopman (2013, p. 95) provides an illuminating account of this broadly Foucauldian employment of genealogy as initiatory rather than constitutive of critique. He argues that it is not so much the fact that, but the way in which something contingently arose which will be of interest, because it is only the latter which makes explicit and opens up to critique the enabling background assumptions of the practice (2013, p. 21). 
The best explanation for why $G$ engages in $P$ is that $P$ is the result of formation process $F P$.

$F P$ is vindicatory, i.e., it offers reasons to prefer $P$ over possible rivals, including the abandonment of $P$.

Therefore, the continuation of $P$ is to that extent justified. ${ }^{18}$

Non-Vindicatory Genealogy:

Group $G$ engages in conceptual practice $P$.

The best explanation for why $G$ engages in $P$ is that $P$ is the result of formation process $F P$.

$F P$ is not vindicatory, i.e., it fails to yield reasons to prefer $P$ over possible rivals, including the abandonment of $P$.

Therefore, $P$ is to that extent rationally contingent.

\section{Subversive Genealogy:}

Group $G$ engages in conceptual practice $P$.

The best explanation for why $G$ engages in $P$ is that $P$ is the result of formation process $F P$.

$F P$ is incriminating, i.e., it offers reasons against the continuation of $P$.

Therefore, the abandonment of $P$ is to that extent justified.

Two noteworthy features of this construal are that it is abductive and tripartite. There are two reasons for reconstructing the genealogies at issue here as a form of abductive reasoning (i.e. reasoning to the best explanation). The first is that it enables us to offer genealogies even where we do not have knowledge about how a given practice actually came about (knowledge which a sound deductive argument would require). The second reason is that to give a sound non-abductive version of the argument, one would need to have established that $P$ is the result of formation process $F P$, which in turn presupposes the existence of formation process $F P$, and this is likely to beg the question against those who dispute that $P$ merits respect and continuation. On the abductive reconstruction, by contrast, the argument is available even in the absence of knowledge; and the existence of the practices acts as evidence for the existence of the formation processes imbuing them with authority. ${ }^{19}$

${ }^{18}$ Here I am generalising to conceptual and evaluative practices a pattern of genetic reasoning spelled out by Klement $(2002,390)$. Klement construes abductive genetic arguments for the truth of a given belief $p$ as having the following form: Person(s) $S$ believes $p$. The best explanation for why $S$ believes $p$ is that $S^{\prime}$ s belief that $p$ is the result of belief-forming process $f$. Belief-forming process $f$ is highly reliable, i.e., it produces true beliefs much more often than it produces false beliefs. Therefore, $\mathrm{S}$ 's belief that $p$ is true.

${ }^{19}$ For this reason, Klement speaks of self-referential abductive reasoning (2002, p. 392). An example is the ending of Tolstoy's Anna Karenina, where Levine perceives his own 
As for distinguishing three possible forms by including the possibility that a genealogy may simply prove non-vindicatory, this points to an important feature of genealogies that take conceptual or evaluative practices rather than beliefs as their objects. We saw that genealogies of genetically justified practices included only two rather than three possible forms. This is because genetically justified practices are matter of representing formation processes as being a certain way. These representations obey the principle of bivalence: they are either true or false. If a genealogy fails to yield evidence that a certain representation of formation processes is true, this will be prima facie evidence of its being false. Hence, genealogies of genetically justified practices will tend to be either vindicatory or subversive. But if we start at the other end, i.e. with the formation process of concepts, values, and practices, we get three rather than two possible argumentative structures. This is because concepts, values, and practices are neither true nor false. They can, however, be evaluated: there can be reasons for or against living by those practices rather than by possible alternatives. They can be more or less apt tools for fulfilling our purposes. But this allows for the possibility that certain aspects of our ways of going on are rationally contingent (and even where our having some form of a practice or concept is not rationally contingent, the specific form it takes in our own cultural situation may be). Hence, a genealogical explanation of how we came to live by a given concept, value, or practice may yield reasons in favour of it, reasons against it, or neither.

This third outcome-finding that our conceptual and evaluative practices are rationally contingent-need not be destabilising. It simply indicates that the practice is rationally contingent, in the sense that it is not justified against possible rivals. ${ }^{20}$ And as Wittgenstein pointed out, to use something without justification does not mean to use it wrongfully. ${ }^{21}$ With conceptual

moral values as evidence for the truth of divine revelation, which in turn vindicates those values (Tolstoy 2014, Part VIII, chs. 12 and 13). Another example is Descartes's argument for the existence of God in the Third Meditation: among the contents of his consciousness, Descartes finds, is the concept of unified perfection, i.e. the concept of God; this concept of unified perfection, he maintains, could not have come from something less than perfect; since he himself is imperfect, the best explanation for his having the concept of God is that it was implanted in him by God himself, as the mark of the maker stamped on his work (Descartes 1996, 3.51). See Williams (2005a, pp. 134-137) for further discussion of this argument.

20 That genealogies need not be normatively determinative is the central point in Koopman (2013, ch. 2).

21 Wittgenstein $(2009, \S 289)$. 
and evaluative practices, the absence of reasons for or against is a stable result which need not be due to epistemic limitations on our part. While it is constitutive of beliefs that they aim at the truth, our tools and practices of sense-making do not aim at being rationally vindicated against all possible rivals. It is a mistake to take contingency to be in itself an objection to our concepts and values. The impression that contingency is problematic derives from two related, but equally erroneous ideas: (i) that we must strive for the set of sense-making practices that is absolutely best; and (ii) that we must do so as characterless selves completely unencumbered by the contingent influences of cultural and biographical circumstance. Against these ideas, we can insist that our task is not to find the concepts and values that are best from a point of view that is as free of contingent historical perspective as possible. ${ }^{22}$ We want the sense-making tools that best make sense of the world to us; but what makes sense to us is in turn a function of who we are and of which concepts shape our concerns, both of which are largely matters of contingent biographical and historical circumstance; this is not a constraint to be overcome, but rather what enables our sensemaking in the first place. The sense-making self cannot be separated from everything that it contingently is-it is not, in the first instance, biased by historical processes, but constructed by them. ${ }^{23}$ There is no characterless self (and even if there were, it would be spectacularly ill-equipped to do what is expected of it). Consequently, it is not an objection to our concepts and values that they are local and contingent. The aim is not that they should be ultimately and timelessly desirable, but that they should have a point for us. This is why revealing their contingency is not in itself subversive.

We thus have two ways of connecting origin and justification: either claims about the origins of practices may affect the space of reasons because these claims concern practices whose authority is itself a function of their formation, or the formation processes themselves are such that knowledge of them can contribute to a vindication or subversion of the practices. Revelations of contingency can sap the authority of practices in the former case, but contingency is normatively inert in the latter case. However, it does not follow that there are no instances of the latter case. Formation process can be authoritative, i.e. they can offer reasons to prefer

${ }^{22}$ I take it that this is the point which Williams (2006, pp. 193-194), in a difficult passage of "Philosophy as Humanistic Discipline," urges against Rorty (1989, chs. 3-4).

${ }^{23}$ Williams (1993, pp. 158-159). 
a practice over possible rivals, and hence genealogies can have normative force independently of how practices claim authority for themselves. The connecting element is the notion of function, which straddles the space of causes and the space of reasons. The question then is how insights into formation processes can yield reasons via insights into functionality.

\section{Functionality and Continuity}

There are many ways of looking at formation processes. We can trace out the meanderings of historical development, date and locate key stages, and map out intricate webs of interconnections between processes. But we can also take a more functional approach and try to identify the salient stabilising factors that led to certain features being retained in virtue of their aptness in serving certain ends. This will reveal the functional origins of the practice, the more or less contingent facts it is rooted in and which it forms a pragmatic response to. This way lies the path from origin to vindication that will be my focus here: genealogy can be vindicatory by yielding a pragmatic vindication - by showing that, given certain needs and purposes and given certain facts about us and our environment, certain ways of going on are rational because apt responses. ${ }^{24}$

Genealogies in this vein try to connect contexts of formation and contexts of justification via functionality. If the question arises, in any given case, whether a conceptual or evaluative practice should be continued, a genealogy can try to answer the question by revealing the function of the practice in relation to our needs and purposes. It does this by presenting the practice as rooted in a set of conditions which together generate a problem to which the practice constitutes a solution. The genealogy thereby shows the practice to be in one sense contingent and in another sense necessary. It shows it to be contingent upon humans and their environment being a certain way; but it also shows it to be practically necessary given these facts, since the challenge they give rise to exerts a strong pragmatic pressure on the remedying practice to arise. If our interest in telling the genealogy is merely historical or explanatory-a matter of grasping how a certain practice could possibly have arisen without divine interference, for

${ }^{24}$ In the sense that a community of practice will have reason to cultivate the practice. My use of the term "rational" is not meant to mark a distinction between the normativity of reasons and the normativity of rationality as drawn, for instance, by Kolodny (2005). 
instance-this will already be enough. But the genealogy will have a more than merely explanatory upshot to the extent that we have reason to think that the root conditions still obtain. Insofar as they do, this will suggest that our present cultural situation involves similar dynamics, and that our present token of the original practice, marked and altered by various contingencies though it may be, still functions, at base, as a response to this same predicament.

The guiding idea of such genealogies is to use insights into why a practice originated - insights yielded by genealogical explanation-to generate insights into what the function of the practice now is. If the function is one we need to see discharged, we shall to that extent have a reason to continue engaging in the practice. If, on the other hand, the practice is one which we do not need to see discharged, we shall have been provided with a reason to abandon the practice. This is an attempt to side-step the genetic fallacy by using the context of formation as a guide to current functionality, which is in turn a relevant consideration when it comes to the practice's justification. A successful inference of this sort, which moves from origin to justification via functionality, involves two steps: one from reflection on how and why a practice originated to its original function; and one from its original function to its current function.

But while the first inference seems easy enough, the second holds difficulties. These difficulties have been clearly brought out by Smyth's (2017) critique of inferences from the original function to the current function of morality. ${ }^{25}$ Smyth argues that if ascriptions of current functionality on the basis of genealogy are to be warranted, the conditions relative to which something originally was functional must still obtain. Smyth thinks, however, that the conditions relative to which the genealogists he discusses take morality originally to have been functional no longer obtain. Therefore, their genealogically derived ascriptions of functionality to contemporary morality are not warranted. ${ }^{26}$

The key difficulty for function-oriented genealogies, then-the "functionalist's burden," as Smyth calls it-is that they presuppose continuity in

${ }^{25}$ The genealogists Smyth focuses on are Kitcher (2011), Joyce (2006), Sinclair (2012), and Prinz (2007), though there is a suggestion that the same difficulties extend to Hume (2000) and Williams (2002). See Smyth (2017, pp. 1130n4, 1131).

${ }^{26}$ Smyth (2017, pp. 1137-1138). 
the conditions relative to which a practice is functional. For our purposes, we can reformulate this constraint as follows:

\section{Continuity:}

Necessarily, for any $P, G$, and $R C_{i}$ : if $R C_{1}, R C_{2}, \ldots R C_{n}$ is the set of root conditions relative to which practice $P$ was originally functional under some description, then the inference from the original function of practice $P$ to its current function in group $G$ is justified only if $R C_{1}, R C_{2}, \ldots R C_{n}$ also obtains in $G$.

When this constraint is not met, genealogically derived ascriptions of functionality exhibit what Smyth calls continuity failure (2017, p. 1137). The attempt to side-step the genetic fallacy by using the context of formation as a guide to current functionality then founders on the fact that the context of formation does not exhibit enough continuity with the present to inform the context of justification.

Smyth acknowledges that there might in principle be a level of description at which root conditions exhibit the continuity necessary to justifying genealogically derived ascriptions of current functionality: we, like our ancestors, live in groups and need to get along and solve various coordination problems (2017, p. 1134). But on Smyth's reconstruction of Kitcher's (2011) and Joyce's (2006) genealogies, the conditions that they in fact appeal to as explanantia stand no chance of obtaining today. Kitcher's explanation only holds for small groups (50 to 150 individuals) in which the probability of a renewed encounter is relatively high and the influence of a given interaction on future interactions is accordingly important- the "shadow of the future," as game theory has it, looms large in each interaction. ${ }^{27}$ Smyth points out that as society grows, the importance of this effect dwindles. Modern societies no longer fulfil the conditions that do the explanatory work in Kitcher's genealogy (2017, p. 1134). Similarly, Joyce's explanation invokes conditiuons in which resources are so scarce that individuals cannot afford to sacrifice greater long-term for lesser short-term gains; and in which group stability is so fragile that any selfish free riding would be severely detrimental to the group's functioning. Again, Smyth sees neither condition fulfilled in modern society (2017, p. 1137).

Yet even if continuously obtaining conditions could be identified, Smyth argues, this would have to be at the cost of their explanatory force-the assumption being that morality would be highly unlikely to evolve in the

\footnotetext{
${ }^{27}$ See, e.g., Lange, Klapwijk, and Munster (2011).
} 
sort of large-scale, relatively secure, and resource-abundant society we live in (2017, p. 1137). Hence, no conditions sufficiently broad to be met by such a modern society would be of help in explaining why morality arose. Smyth's conclusion is that moral genealogists must choose between explaining morality's emergence and uncovering its current function. If they go for the former, they will diagnose morality's functionality relative to conditions which no longer obtain. If they go for the latter, the most promising genealogical path to functional ascriptions will be one which focuses on modern history rather than on our Pleistocene ancestors; but then they will learn little about why morality originally arose. They cannot have it both ways.

Two qualifications are in order here. First, genealogies do not depend on Continuity being satisfied society-wide. It may be enough if the conditions in response to which a practice arose exhibit only partial continuity in certain sub-domains of society, such as the family or the football-club. Second, it is precisely the point of some function-oriented stories about how our practices originated that Continuity fails to obtain-in recent years, evolutionary psychology has pursued the idea that certain traits originated as functional adaptations to an ancestral environment which markedly differs from our present-day environment, leaving us with many dysfunctional tendencies or biases.

Nevertheless, Smyth is surely right that the Continuity constraint is the crucial hurdle for genealogies aiming to reveal the current functionality-as opposed to dysfunctionality — of practices, and if Smyth's critique applies not only to Kitcher's (2011) and Joyce's (2006) genealogies, but to all genealogies in this vein, it seems that they can avoid the genetic fallacy only at the cost of foundering on continuity failures. Yet as we shall see, the genealogies of Craig (1990), Williams (2002), and Fricker (2007) indicate how genealogy can avoid continuity failures.

\section{Avoiding Continuity Failures}

There are two ways in which genealogies can avoid continuity failures. The first is to operate at high levels of description which abstract away from the particulars of given token situations and bring into view features extending over a wide range of situations. Call this the high level of description strategy. The second is to show that the need for the practice in question-the focal 
practice- has a firm basis in and derives from basic needs humans can be assumed to have anyway. Call this the anchoring in human nature strategy. Both of these labels will seem rather off-putting to readers suspicious of sweeping generalisations or speculative just-so stories about human nature. Yet while the labels may be alarming, I shall argue that the strategies they label are executed in ways that make them reassuringly modest in the commitments they undertake.

The genealogies of Craig, Williams, and Fricker pursue both of these strategies together: they focus on the general and anchor it in the basic. For the sake of clarity, we can prise these two strategies apart. The first strategy of these genealogists is to operate at such a high level of description that they do not (in the first instance) make reference to any particular point in history at all. They start out from what philosophical tradition has come to call, perhaps misleadingly, a "state of nature." But this is not a depiction of life in the Pleistocene. Nor is it any other point on the timeline of history. It is best understood as a model, an idealising representation of functional dynamics at a level of abstraction familiar from game theory and rational choice theory. ${ }^{28}$ The state of nature depicts how a set of root needs under certain root circumstances generate further needs, including, centrally, a focal need to which a prototypical form of the practice we are interested in - the focal practice-constitutes a rational because functional response. At this level of abstraction, the model is no more a model of one point on the timeline of history than of any other. As Craig notes: "Reference to mankind's prehistory was no essential part of my argument" (2007, p. 192). What his genealogy was meant to show was that "the core of the concept of knowledge is an outcome of certain very general facts about the human situation" (1990, p. 10). Similarly, Williams insists that the state of nature is "not intended to represent some early hominid environment" (2014b, p. 411). Rather, it is part of "a fictional story which represents a new reason for action as being developed in a simplified situation as a function of motives, reactions, psychological processes which we have reason to acknowledge already" (2000, p. 159). And Fricker, who takes up and develops Craig's and Williams's state-of-nature models, understands the device as a "maximally ahistorical setting," a construct designed to characterise our most basic needs and what they entail $(2007,108-9)$. This means that the state of nature

${ }^{28}$ See Kusch $(2009,2011,2013)$ and Kusch and McKenna (Forthcoming) for a reading of Craig's genealogy along these lines. 
can be as much a model of the present as of a given earlier society. Given this, the question is not so much whether one can, in principle, infer from that model to the present-that comes for free with its being a model of a timespan that includes the present: it is the point of the model that it permits this kind of inference. The question is whether it is a good model.

Such model-based genealogies make ascriptions of current functionality not on the basis of claims about a certain period in our past, but on the basis of generic models of our most general predicaments. Insofar as they are genealogies at all, they are genealogical inquiries into structural origins, i.e. into the highly general facts about us and our environments that our practices are rooted in. ${ }^{29}$ Model-based genealogies can elucidate and vindicate a practice by presenting it as structurally rooted in, and in that sense as originating in, a set of conditions, the root conditions, which together generate a focal need to which the focal practice constitutes a solution. The root conditions appealed to by Craig, Williams, and Fricker-a need for information about $p$, or a need for cooperation in $\varphi$-ing-are so highly general and abstractly characterised that they can be plausibly be thought to obtain in anything recognisable as a human society. This is how the high level of description strategy aims to secure continuity: by characterising the functional dynamics out of which practices arise and by which they are held in place at a level of abstraction which renders them applicable to an extremely wide range of situations.

The second strategy aims to provide reasons for thinking that the functional dynamics in question are at work in our present situation. It does this by anchoring the focal need in question in the most basic demands of human nature. This is why these genealogies typically start out from what we take ourselves to know about human beings and their situation quite generally. We can grant that humans have had very different goals and interests at different times, but some of their most basic needs can plausibly be thought to exhibit more continuity. Craig starts out from needs "so general ... that one cannot imagine their changing whilst anything we

\footnotetext{
${ }^{29}$ There are of course other philosophical methods that deploy generic models and general facts, and I would not wish to claim that all of these methods are specifically genealogical. Rather, I claim that a specific set among the various philosophical enterprises that call themselves "genealogical" is really best understood as being in the business of making sense, in the light of generic models and general facts about the kind of creatures we are, of why we came to think and value as we do. I am grateful to an anonymous reviewer for pressing me on this point.
} 
can still recognize as social life persists" (1990, p. 10; 2007, p. 191). Williams also seeks to ground his genealogy in "universal considerations" (2002, p. 172), in "motivations that people must be granted to have anyway" (2002, p. 33). And Fricker speaks of "absolutely basic epistemic needs" (2007, p. 112), and remarks that genealogies can help us understand how our present practices form contingent manifestations of our most basic predicaments (1998, p. 165).

It is true that substantial commitments will thereby be undertaken about what kinds of creatures humans are and what kinds of environments they live in. Genealogical explanations, like all explanations, have to start somewhere and take certain things for granted. But there are two respects in which Craig, Williams, and Fricker execute their genealogical narratives in a way that allows them to take as little for granted as possible. They do not simply settle on a practice and then paint an innate need for just that practice into our picture of human nature.

On the one hand, what they take for granted are structural needs like the need to gather and share information about the immediate environment or the need to avoid conflict: these are second-order needs that grow out of the relations between individuals' first-order needs (such as their need for various types of foods, goods, and tools). Structural needs are to a large extent counterfactually robust, because they are overwhelmingly insensitive to the content of first-order needs-almost irrespective of what their first-order needs are under given circumstances, humans will have a strong interest in gathering and sharing information about their immediate environment and in avoiding conflict. ${ }^{30}$ If there are any needs that we can be confident humans beings have anyway, structural needs are good candidates-if only because they already grow out of the most trivial human needs, such as the need to locate and have access to sources of water.

On the other hand, these structural needs then form a basis from which to derive further needs, showing how one practical exigency entails the next, until one reaches the need to which the focal practice forms a direct functional response. The need for the focal practice is thus not simply postulated as being part of human nature, but shown to be entailed from more primitive

\footnotetext{
${ }^{30}$ Indeed, there is a limit to how different a form of life can be while remaining intelligible as a variation on ours. Differences must ultimately be made sense of in terms of similarities-variations on human life are only recognisable as such against the backdrop of a shared set of features that make them variations on human life.
} 
and less controversial needs. This way of proceeding sets the genealogies of Craig, Williams, and Fricker apart from much-maligned just-so stories about human nature such as that of Randy and Nancy Thornhill (1983, 1992), which raised eyebrows by declaring "men's tendency to rape" to form an innate part of human nature. ${ }^{31}$ The genealogies of Craig, Williams, and Fricker are more modest in their assumptions in that they demonstrably but fallibly derive the needs they are interested in from structural needs that raise no eyebrows when presented as in some sense inscribed in human nature.

There is a point to this anchoring in human nature strategy, in particular, when focal needs we are less confident we have can be derived from root needs we are more confident we have. It may not at all be obvious that we need the concept of knowledge, the virtue of truthfulness, or the virtue of testimonial justice, because they perform functions which render them indispensable to creatures like us. When questions arise over whether we should continue to cultivate these conceptual practices, or whether we might and perhaps should abandon them with impunity, for instance because we suspect them to be fetishised relics of a not yet thoroughly disenchanted world, revealing these practices' instrumental relations to some of our most basic needs acts as a powerful vindication of them: it frees them of suspicion by showing them to be rooted in basic human needs and thereby (in a sense I shall come back to) provides reasons for us to continue to cultivate these practices.

These genealogies thus try to meet the Continuity condition by offering reasons to think that the focal practice is continually required and held in place by focal needs to which it responds, and that these are derivative of needs so basic that human beings can be assumed to have them anyway. The question raised by Continuity is whether we now have such focal needs, and rather than to simply assume that this is the case, these genealogies provide an argument to the effect that the focal needs are rooted in and constitute structural corollaries to certain basic roots needs which can more plausibly be assumed to be needs we have anyway. They try to meet the Continuity condition by offering reasons to think that the focal practice is continually required and held in place by needs to which it responds,

${ }^{31}$ See Hufendiek (Forthcoming) for a nuanced discussion of this and other controversial inscriptions of traits into human nature and of how these have been exploited as bases for the critique of naturalism in the nature-nurture debate. 
and that these are derivative of needs so basic that human beings can be assumed to have them anyway. Where these instrumental relations between a given practice and our basic needs is not transparent to us, genealogical explanations offer perspicuous derivations of the need for a certain practice from needs so basic and so general that they can, with some plausibility, be assumed to be continuous over extremely wide ranges of situations, including ours. The genealogies thereby give us reason to think that the focal needs are indeed with us. This does not free us entirely from the burden of making substantial assumptions about human nature, but it greatly reduces the load. It highlights the respects in which a given element of our present cultural situation forms a practical response to a basic predicament. It shows it to be rooted in functional dynamics that are most perspicuously represented with the help of a prototypical practice, the present manifestation of which, marked and altered by history though it may be, still functions, at base, as a response to this same predicament. The anchoring in human nature strategy thus aims to secure continuity by deriving the focal need to which the focal practice responds from basic needs humans have anyway.

The importance of these two strategies to the success of model-based genealogies becomes particularly apparent if their argumentative structure is laid out as follows:

\section{Model-Based Genealogy:}

(P1) In a prototypical group $G$, a set of root needs $R N_{1}-R N_{n}$ under root circumstances $R C_{1}-R C_{n}$ generate a practical problem.

(P2) This generates a pragmatic pressure on $G$ to solve the problem: the focal need $F N$.

(P3) Prototypical practice $P$ would meet the focal need $F N$ by discharging function $F$.

(P4) $P$ could develop quite naturally, i.e., out of the capacities we are prepared to grant $G$ anyway, via the set of steps $S_{1}-S_{n}$.

(C1) Therefore, $P$ would be bound to develop in any $G$ that persists.

(C2) Therefore, it is rational for $G$ to engage in $P$ in order for $F$ to be discharged in $G$ (in the sense that people with these needs under these circumstances would welcome and, if they could do so, aim for engagement in $P$ with a view to the discharge of $F$ ). 
(P5) In the actual group $G^{*}$, there are close analogues to $R N_{1}-R N_{n}$ and $R C_{1}-R C_{n}$, namely $R N_{1}^{*}-R N_{n}^{*}$ and $R C_{1}^{*}-R C_{n}^{*}$.

(C3) Therefore, it is also rational for $G^{*}$ to engage in $P^{*}$, the closest analogue to $P$ in $G^{*}$, in order for $F$ to be discharged.

(C4) Therefore, the best explanation for why we go in for $P^{*}$ is that it discharges function $F$.

(C5) Therefore, there is a prima facie reason for $G^{*}$ to continue $P^{*}$, and $P^{*}$ is to that extent vindicated.

This reconstruction lays out how model-based genealogy affects the space of reason by showing us that given that we share certain needs, we have reasons to engage in certain reasoning-practices. What the reconstruction of model-based genealogies also brings out is that their soft underbelly is $\mathrm{P}_{5}$, which assumes that the root needs and root circumstances in fact obtain in our present situation. It is this premise which the two strategies aim to strengthen: the variables $R N_{1}-R N_{\mathrm{n}}$ and $R C_{1}-R C_{\mathrm{n}}$ are assigned to facts about human beings and their environment that stand a good chance of obtaining anyway, i.e. independently of the particulars a given situation, because they are basic structural facts about the human situation picked out under highly general and abstract descriptions.

The danger for this way of proceeding is that the explanations will end up being too abstract and general to be informative. It is no coincidence that genealogies in the vein of Craig, Williams, and Fricker take a piece-meal approach: instead of trying to identify, wholesale, the function of entire domains of human thought and action, they proceed one concept at a time, singling out a particular thread within the tangle of our conceptual practices-such as knowledge, truthfulness, or testimonial justice-and following it to its moorings in the needs of concept-users. Although this may not be a necessary condition on the method's effectiveness, it contributes to it in two ways. On the one hand, informativeness is likely to decrease as the level of description at which the genealogy works increases in abstraction. Moreover, as we saw Smyth acknowledge, securing continuity will already require working at a fairly high and abstract level of description. This suggests that the way to maximise informativeness while retaining continuity is to keep the object of investigation narrow and concrete by philosophy's standards - to try and show that any society will need a particular concept or value in order to solve a specific, well-delineated, and perhaps even 
formalisable coordination problem rather than to show that any society will need some form of ethical consciousness in order to solve coordination problems in some form. On the other hand, working piecemeal leaves room for the idea that our practices may be an assemblage of individually functional elements, each tailored to its specific purpose, which do not all fit together into a harmonious, functional whole. ${ }^{32}$ Insofar as this is the case, it must mean that we are bound to miss the tensions and conflicts between practices that cannot be pressed all the way together if we do not work piecemeal; and it gives further succour to the idea that insofar as morality as a whole can be said continually to perform a function at all, that function is likely to be too indeterminate to retain much informative value.

In sum, genealogies stand a good chance of overcoming continuity failures if they (i) derive functional conclusions not from the Pleistocene, or from any other however vaguely situated period in hominid history, but from highly abstract functional models; (ii) use these models to identify the focal practice's structural roots in basic human needs and what they entail; and (iii) take a piece-meal approach. The conclusion supported by a successful enterprise along these lines will be that some practice we now engage in forms a functional response to a basic problem-that it serves a point relative to needs we are bound to share.

Such genealogies avoid continuity failures, because they operate at a high level of description while anchoring the focal needs on which their functional ascriptions depend, and which prima facie do not seem likely to exhibit the necessary continuity, in more basic needs, which do. They make ascriptions of current functionality, not on the basis of claims about a certain period in our past, but on the basis of abstract models of our most basic predicaments. The ascriptions of functionality are then genealogically derived from structural origins rather than from historical origins, though if the structures in question are as continually part of the human situation as the state-of-nature model represents them as being, these structural origins will in turn help us understand the practice's actual historical origins. The crucial point, however, is that these genealogies do not assume continuity in the practical demands we face, because precisely what they are is attempts

\footnotetext{
32 A point which Williams, following Isaiah Berlin, presses in several places $(1981 ; 2011$,
} p. 170). 
to identify bases of continuity in those demands. They are not arguments depending on continuity, but arguments for it.

It follows from such a broadly functionalist construal of the method of genealogy that it will be, in the first instance, vindicatory. Asking why we go in for a certain practice first points us to the respects in which it does something for us. It would of course be Panglossian optimism to think that this is the end of the story. As research on the emergence of so-called "bad norms" indicates, there are many ways in which functional dynamics can issue in something that does more harm than good. ${ }^{33}$ But for our present concerns, the important point is that a genealogical explanation satisfying the Continuity constraint would entail that however much harm a practice may cause, it must also still continually prove its worth as a response to the basic predicament which the genealogy represents us as facing in virtue of our sharing certain basic needs.

The precise relation of functional insights to normative conclusions is notoriously complex, and I cannot hope to fully explicate it here, but I want to close with three observations about the general shape that this relation takes in model-based genealogies. First, at the most general level, what these genealogies do is to reveal how some practice helps us to live, which they achieve by taking something we are less confident we need (e.g., the concept of knowledge, the value of truth, or the virtue of epistemic justice) and deriving it as a practical corollary from something we are more confident we need (e.g., information about our immediate environment). This can be thought of as a non-foundationalist strategy: eschewing attempts to derive the concepts we should live by from absolute rational foundations in Platonic Forms or universal reason, it instead tries to foster allegiance to certain conceptual practices by showing that they promote material that already commands broad allegiance. The uncontroversial and basic human needs that figure at the root of Craig's, Williams's, and Fricker's genealogies are paradigmatic examples of such material. Few will be disposed to deny that we have these needs; what they might be disposed to deny is that these needs bring with them certain problems that certain conceptual practices in turn equip us to solve; and this is where the genealogical derivations come in, as narratives designed to bring out just how these conceptual

33 Brennan et al. (2013, ch. 8); Rosenberg (2016). 
practices in fact serve ends that the narratives' addressees are already fully committed to pursuing.

Second, the normative force of these functional insights will be limited in various ways: they can give us reasons to cultivate certain concepts and values tout court, but they cannot give us reasons for particular actions or beliefs - they cannot tell one, say, whether to be truthful to someone on a particular occasion. The insight into the basic functionality of a system of epistemic division of labour based on the virtues of truthfulness, as Williams himself notes, by itself "takes us nowhere at all" (2002, p. 84) insofar as we want to know, when the question arises with regard to particular pieces of information, whether we should continue to work the system. A related limitation derives from the fact that the reasons yielded by genealogies will often-roughly, whenever the practical value of my doing something lies in its value to others rather than to myself-be in the first instance reasons for the collective to cultivate certain practices rather than reasons for the individual to participate in those practices.

Yet neither limitation brings the normative force of such genealogies down to zero, especially on a realistic picture of who their addressees might be. When genealogies' addressees are real people rather than creatures from the demonology of philosophy, such as the complete amoralist, they can provide reasons for the individual by providing reasons for the collective, notably via the thought that if everyone always defected, the beneficial practice would break down. This imagined universalisation is itself an ethical thought, and will therefore be no help against the amoralist. ${ }^{34}$ Yet when the addressee is someone who is already part of an ethical community, but whose confidence in a particular practice is wavering (due perhaps to suspicions fostered by an austere naturalism or by postmodern irony), a genealogy can increase that individual's confidence in the disposition to engage in certain conceptual practices and to treat certain considerations as reasons. ${ }^{35}$ What Williams thought was true of any attempt to justify the ethical life is certainly true of genealogical vindications: their "aim

\footnotetext{
34 See Williams (1973, pp. 252-253; 2011, p. 31).

35 Such reasons to cultivate dispositions remain importantly different from pragmatic reasons for belief in the sense of reasons purporting to show directly that a given statement is true. The reasons I am concerned with are reasons to think in terms of certain concepts at all, whereas the reasons at issue in recent debates over pragmatic reasons for belief are primarily reasons to think that particular contents articulated in terms of given concepts are true (see Reisner (2009, Forthcoming) for an overview).
} 
is not to control the enemies of the community or its shirkers but, by giving reason to people already disposed to hear it, to help in continually creating a community held together by that same disposition" (2011, p. 31). Genealogies are not instruments of conversion. But they can promote self-understanding, and thereby strengthen the confidence of those who are, in some measure, already disposed to think and value in terms of the concepts which the genealogies address.

Finally, it is worth highlighting that such genealogies need not focus exclusively on instrumental reasons. They can also accommodate and strengthen our confidence in non-instrumental reasons. Williams's stateof-nature model, for example, shows us that nearly any human community has instrumental reasons to encourage dispositions of truthfulness (in the prototypical form of dispositions of Accuracy and Sincerity) in its members, because this contributes to the efficient pooling of information and thus, in the long run, to the welfare of each member. But a purely functional explanation which leaves it at that is bound to be unsatisfactory. On the one hand, the explanation will jar with the manifest fact that for us, truthfulness, like justice or loyalty, is more than a means to an end. Reducing it to its instrumental value unduly ignores its intrinsic value. On the other hand, if we persist in understanding truthfulness in purely functional terms, we have trouble seeing how it could have been stable enough to fulfil its purpose: if people were truthful only for instrumental reasons, the practice of truthfulness would become vulnerable to free riders. Why should one, on a given occasion, exhibit dispositions of truthfulness that promise to pay in the long run if by making an exception, on this particular occasion, one can reap some extra benefits for oneself without compromising the communal practice of truthfulness? ${ }^{36}$ This familiar line of thought is all

36 This echoes Williams's critique of indirect utilitarianism (2011; 1973): the recommendation of non-utilitarian rules on strictly utilitarian grounds is unstable under reflection due to the lack of fit between the spirit of the justification and the spirit it justifies. A structurally similar argument that focuses on the threat of unintelligibility rather than instability is advanced by Müller (2003). But the difficulty is not peculiar to utilitarianism: Gauthier's (1986) argument that reflection provides players in the Prisoners' Dilemma with a rational basis to acquire dispositions to justice suffers from the same difficulty. As Williams puts it, the "lack of fit between the spirit of justification and the spirit being justified is so radical that, if the construction is exposed to reflection at all, it is bound to unravel" (2002, p. 91). Kolodny (2005) also discusses the problem: "Why is there reason to follow, in this particular case, the rule that promises utility over the long run, if violating it, in this particular case, promises even more utility?" (p. 543). Like Williams, he comes to the conclusion that what is needed to move the individual is an intrinsic reasonto follow the rule on each and every occasion (pp. 544-45). 
the more devastating in the case of truthfulness, since the practical value of $m y$ truthfulness - especially the practical value of my Sincerity-lies predominantly in its value to other people. To escape this free rider problem and to stabilise truthfulness, therefore, "there should be some dispositions to think that telling the truth (to the right people, on the right occasions) is in itself a good thing" (Williams 2014b, p. 408). Only in communities in which people are disposed to assign value to truthfulness per se, thus ceasing to see it as merely functional, can this conceptual practice fulfil its function. It must outgrow its mere functionality in order to be functional: intrinsic reasons are required that will give one reason to be truthful even when doing so involves forsaking opportunities for personal gain in other respects. By helping us understand this, model-based genealogies can explain why and, by involving themselves in history, how and in connection with which other values we came to think in terms of intrinsic reasons now and around here (some cultures make sense of the intrinsic value of truthfulness in terms of honour; others in terms of freedom). ${ }^{37}$

Among the strengths of such genealogies is their capacity to avoid emphasising instrumental reasons at the expense of non-instrumental reasons. As Craig pithily puts it, "with genealogy, we need neither overstress nor overlook function" (2007, p. 198). Genealogies offer us "explanation with reduction" (Williams 2002, p. 90), providing functional explanations of why we came to engage in certain practices which, by highlighting the uses of intrinsic values or the benefits of being "bloody-minded rather than benefit-minded" (Williams 2002, p. 59), issue in vindicatory explanations of our having further, non-instrumental or intrinsic reasons to engage in those practices. This falls short of yielding intrinsic reasons we did not have before. But the aim of a genealogy like Williams's is not to give truthfulness intrinsic value; it is to vindicate it as the intrinsic value it already is: to give it a bill of health, showing that it makes sense that creatures like us should accept considerations connected to truthfulness as intrinsic reasons in order to strengthen the addressees' confidence in those reasons. ${ }^{38}$

The conclusion we reach is that there are genealogical paths from origin to justification which neither commit the genetic fallacy nor suffer from con-

37 See Kusch (2009) and Reynolds (2017) for an account of how a similar structure can be discerned in Craig's genealogy of the concept of knowledge.

${ }^{38}$ Spelling out more fully how and in what sense exactly genealogical explanation can vindicate new reasons for action as given by intrinsic values requires a paper of its own. I offer a fuller picture of Williams's way of doing it in Queloz (Forthcoming). 
tinuity failure. I have focused in particular on sketching an interpretation of the genealogies offered by Craig, Williams, and Fricker as model-based genealogies tailored to the task of showing that a practice we might have thought of as a contingent outgrowth of our local situation and history in fact functions as an indispensable response to continual practical exigencies. I have argued that this involves an inference from the structural origins of a practice in a generic predicament to the modest but genuine vindication of our local manifestation of it. Such an inference might still be wrong, of course. Yet on the interpretation offered here, the problem will then not be that it has subtly trespassed against the canons of reasoning, but simply that it is unsound.

\section{Acknowledgements}

I am grateful to the editors of Synthese and to three anonymous referees for their helpful comments. I would also like to thank Markus Wild, Martin Kusch, Rebekka Hufendiek, Damian Cueni, Jelscha Schmid, Lucius Caviola, Andreas Schönenberger, and audiences in Basel and Linescio for discussions and for their valuable feedback. Work on this paper was supported by grant P0BSP1_162025 of the Swiss National Science Foundation.

\section{Bibliography}

Anderson, E. (2001). Unstrapping the Straitjacket of 'Preference': A Comment on Amartya Sen's Contributions to Philosophy and Economics. Economics and Philosophy, 17(1), 21-38.

Blackburn, S. (2016). The Oxford Dictionary of Philosophy (3ed.). Oxford: Oxford University Press.

Brennan, G., Eriksson, L., Goodin, R. E., \& Southwood, N. (2013). Explaining Norms. Oxford: Oxford University Press.

Craig, E. (1990). Knowledge and the State of Nature: An Essay in Conceptual Synthesis. Oxford: Clarendon Press.

Craig, E. (1993). Was wir wissen können: Pragmatische Untersuchungen zum Wissensbegriff. Wittgenstein-Vorlesungen der Universität Bayreuth. Frankfurt am Main: Suhrkamp.

Craig, E. (2007). Genealogies and the State of Nature. In A. Thomas (Ed.), Bernard Williams (pp. 181-200). Cambridge: Cambridge University Press. 
Crouch, M. A. (1991). Feminist Philosophy and the Genetic Fallacy. Hypatia, 6(2), 104-117.

Crouch, M. A. (1993). A 'limited' defense of the genetic fallacy. Metaphilosophy, 24(3), 227-240.

Descartes, R. (1996). Oeuvres de Descartes. Paris: Vrin.

Dutilh Novaes, C. (2015). Conceptual genealogy for analytic philosophy. In J. A. Bell, A. Culrofello, \& P. M. Livingston (Eds.), Beyond the AnalyticContinental Divide (pp. 75-110): Routledge.

Finken, B. (2012). Nietzsche versus the Genetic Fallacy. Journal of Nietzsche Studies, 43(2), 305-315.

Foucault, M. (1971). Nietzsche, la généalogie, l’histoire. In S. Bachelard (Ed.), Hommage à Jean Hyppolite (pp. 145-172). Paris: Presses Universitaires de France.

Fraser, N. (1981). Foucault on modern Power: empirical insights and normative Confusions. In N. Fraser (Ed.), Unruly Practices: Power, Discourse and Gender in Contemporary Social Theory (pp. 17-34).

Fricker, M. (1998). Rational Authority and Social Power: Towards a Truly Social Epistemology. Proceedings of the Aristotelian Society, 98(2), 159-177.

Fricker, M. (2007). Epistemic Injustice: Power and the Ethics of Knowing. Oxford and New York: Oxford University Press.

Fricker, M. (2016). What's the Point of Blame? A Paradigm Based Explanation. Nô̂s, 50(1), 165-183.

Fricker, M. (Forthcoming). Forgiveness: An Ordered Pluralism. Australasian Philosophical Review.

Gauthier, D. (1986). Morals by Agreement. Oxford: Oxford University Press.

Glock, H.-J. (2008a). Analytic Philosophy and History: A Mismatch? Mind, 117(468), 867-897.

Glock, H.-J. (2008b). What is Analytic Philosophy? Cambridge: Cambridge University Press.

Goudge, T. A. (1961). The genetic fallacy. Synthese, 13(1), 41-48.

Gutting, G. (2005). Foucault. Oxford: Oxford University Press.

Hamblin, C. L. (2004). Fallacies. Newport News: Vale Press.

Hanson, N. R. (1967). The Genetic Fallacy Revisited. American Philosophical Quarterly, 4(2), 101-113.

Hoy, D. C. (1994). Nietzsche, Hume, and the Genealogical Method. In R. Schacht (Ed.), Nietzsche, Genealogy, Morality: Essays on Nietzsche'sOn the 
Genealogy of Morals (pp. 249-267). Berkeley: University of California Press.

Hufendiek, R. (Forthcoming). The Essentialist Fallacy: A Misguided Critique of Naturalism in the Nature-Nurture Debate.

Hume, D. (2000). A Treatise of Human Nature. Oxford: Oxford University Press.

Joyce, R. (2006). The Evolution of Morality. Cambridge, Mass., and London, England: MIT Press.

Kaplan, A. (2002). The Conduct of Inquiry: Methodology for Behavioural Sciences. New Brunswick: Transaction.

Kim, C.-T. (1990). A Critique of Genealogies. Metaphilosophy, 21(4), 391-404.

Kitcher, P. (2011). The Ethical Project. Cambridge, Mass.: Harvard University Press.

Klement, K. C. (2002). When Is Genetic Reasoning Not Fallacious? Argumentation, 16(4), 383-400.

Kolodny, N. (2005). Why Be Rational? Mind, 114(455), 509-563.

Koopman, C. (2013). Genealogy as Critique: Foucault and the Problems of Modernity. Bloomington and Indianapolis: Indiana University Press.

Kusch, M. (2009). Testimony and the Value of Knowledge. In Pritchard, Haddock, \& Millar (Eds.), Epistemic Value (pp. 60-94): Oxford: Oxford University Press.

Kusch, M. (2011). Knowledge and Certainties in the Epistemic State of Nature. Episteme, 8(1), 6-23.

Kusch, M. (2013). Naturalized Epistemology and the Genealogy of Knowledge. In M. Lenz, \& A. Waldow (Eds.), Contemporary Perspectives on Early Modern Philosophy: Nature and Norms in Thought (pp. 87-100). Dordrecht and New York: Springer.

Kusch, M., \& McKenna, R. (Forthcoming). The Genealogical Method in Epistemology. Synthese.

Lange, P. A. M. V., Klapwijk, A., \& Munster, L. M. V. (2011). How the shadow of the future might promote cooperation. Group Processes and Intergroup Relations, 14(6), 857-870.

Lavine, T. Z. (1962). Reflections on the genetic fallacy. Social Research, 29(3), 321-337.

McGinn, C. (2003). Isn't It the Truth? The New York Review of Books, L(6). 
Müller, O. L. (2003). Can They Say What They Want? A Transcendental Argument Against Utilitarianism. Southern Journal of Philosophy, 41(2), 241-259.

Nagel, T. (1997). The Last Word (Philosophical Essays). Oxford and New York: Oxford University Press.

Nagel, T. (2009). Willams: Philosophy and Humanity. In Secular Philosophy and the Religious Temperament (pp. 139-146). Oxford and New York: Oxford University Press.

Pashman, J. (1970). Is the genetic fallacy a fallacy? Southern Journal of Philosophy, 8(1), 57-62.

Prinz, J. J. (2007). The Emotional Construction of Morals. Oxford: Oxford University Press.

Queloz, M. (2017a). Does Philosophy Have a Vindicatory History? Bernard Williams on the History of Philosophy. Studia Philosophica, 76, 137-152.

Queloz, M. (2017b). Nietzsche's Pragmatic Genealogy of Justice. British Journal for the History of Philosophy, 25(4), 727-749, doi:10.1080/09608788.2016.1266462.

Queloz, M. (Forthcoming-a). Nietzsches affirmative Genealogien. Deutsche Zeitschrift für Philosophie.

Queloz, M. (Forthcoming-b). Williams's Pragmatic Genealogy and SelfEffacing Functionality. Philosophers' Imprint.

Queloz, M. (Manuscript). Nietzsche's Vindicatory English Genealogy of Truthfulness.

Reisner, A. (2009). The Possibility of Pragmatic Reasons for Belief and the Wrong Kind of Reasons Problem. Philosophical Studies, 145(2), 257-272.

Reisner, A. (Forthcoming). Pragmatic Reasons for Belief. In D. Star (Ed.), The Oxford Handbook of Reasons and Normativity (pp. ch. 30). Oxford: Oxford University Press.

Reynolds, S. L. (2017). Knowledge as Acceptable Testimony. Cambridge: Cambridge University Press.

Rorty, R. (1989). Contingency, Irony, and Solidarity. Cambridge: Cambridge University Press.

Rosenbaum, S. (2002). Sustaining Pragmatism's Critique of Epistemology. In P. B. a. J. Geller (Ed.), Conversations with Pragmatism. New York: Rodopi. Rosenberg, A. (2016). Functionalism. In L. McIntyre, \& A. Rosenberg (Eds.), The Routledge Companion to Philosophy of Social Science. London: Routledge. 
Salmon, W. C. (1973). Logic. Englewood Cliffs: Prentice-Hall.

Sinclair, N. (2012). Metaethics, Teleosemantics and the Function of Moral Judgements. Biology and Philosophy, 27(5), 639-662.

Smyth, N. (2017). The Function of Morality. Philosophical Studies, 174(5), 1127-1144.

Sober, E. (1994). Prospects for an Evolutionary Ethics. In From a Biological Point of View (pp. 93-113). Cambridge: Cambridge University Press.

Srinivasan, A. (2015). The Archimedean Urge. Philosophical Perspectives, 29(1), 325-362.

Thornhill, R., \& Thornhill, N. (1983). Human Rape. An Evolutionary Analysis. Ethology and Sociobiology, 4, 137-173.

Thornhill, R., \& Thornhill, N. (1992). The Evolutionary Psychology of Men's Coercive Sexuality. Behavioral and Brain Sciences, 15, 363-421.

Tolstoy, L. (2014). Anna Karenina (M. Schwartz, Trans.). New Haven: Yale University Press.

Ward, A. C. (2010). The Value of Genetic Fallacies. Informal Logic, 30(1), $1-33$.

Wiener, P. P. (1946). Logical Significance of the History of Thought. Journal of the History of Ideas, 7(3), 366-373.

Williams, B. (1973). Egoism and Altruism. In Problems of the Self (pp. 250-265). Cambridge: Cambridge University Press.

Williams, B. (1981). Conflicts of Values. In Moral Luck (pp. 71-82). Cambridge: Cambridge University Press.

Williams, B. (1993). Shame and Necessity. Berkeley: University of California Press.

Williams, B. (2000). Naturalism and Genealogy. In E. Harcourt (Ed.), Morality, Reflection, and Ideology (pp. 148-161). Oxford: Oxford University Press.

Williams, B. (2002). Truth and Truthfulness: An Essay in Genealogy. Princeton: Princeton University Press.

Williams, B. (2005a). Descartes: The Project of Pure Enquiry. London: Routledge.

Williams, B. (2005b). From Freedom to Liberty: The Construction of a Political Value. In G. Hawthorne (Ed.), In the Beginning Was the Deed: Realism and Moralism in Political Argument (pp. 75-96). Princeton and Oxford: Princeton University Press. 
Williams, B. (2006). Philosophy as a Humanistic Discipline. In A. W. Moore (Ed.), Philosophy as a Humanistic Discipline (pp. 180-199). Princeton and Oxford: Princeton University Press.

Williams, B. (2011). Ethics and the Limits of Philosophy. Oxford: Taylor and Francis.

Williams, B. (2014a). The Last Word, by Thomas Nagel. In M. Woods (Ed.), Essays and Reviews 1959-2002 (pp. 371-387). Princeton: Princeton University Press.

Williams, B. (2014b). Why Philosophy Needs History. In M. Woods (Ed.), Essays and Reviews 1959-2002 (pp. 405-412). Princeton: Princeton University Press.

Williams, B., \& Smart, J. J. C. (1973). Utilitarianism: For and Against. Cambridge: Cambridge University Press.

Wittgenstein, L. (2009). Philosophical Investigations. Chichester, U.K.: WileyBlackwell. 